\title{
CONTRIBUIÇÃO AO ESTUDO DA RESSEDIMENTAÇÃO NO SUBGRUPO ITARARÉ: UM GUIA TEMÁTICO DE CAMPO
}

\author{
ERCÍlIO G. GAMA, Jr.*, JOSÉ A J. PERINOTTO*, HÉLIO J.P.S. RIBEIRO** e EDUARDO K. PADULA***
}

\begin{abstract}
CONTRIBUTION TO THE STUDY OF RESEDIMENTATION IN THE ITARARÉ SUBGROUP: A THEMATIC FIELD GUIDE BOOK. This paper is the complementary contribution to the resedimentation facies analysis in the Permo-Carboniferous Itararé Subgroup, in conjunction to the preceding paper. Seven didatic outcrops were selected, described and documented at Porto Feliz city region in São Paulo State. These outcrops represent in a typical way the overall facies tracts generated by the gravitational processes took place in both confined and unconfmed conditions. The recommended guide follows the continuous facies transition in each one of the
\end{abstract} two facies tracts.

Keywords: Itararé Subgroup, resedimentation, field guide, Paraná Basin, Permian, Permo-Carboniferous, sedimentary geology.

RESUMO Este guia de campo complementa a contribuição oferecida no artigo associado sobre o tema ressedimentação no Subgrupo Itararé. São selecionados, descritos e documentados sete afloramentos bastante didáticos na região de Porto Feliz, Estado de São Paulo, que representam, tipicamente, as fácies geradas por processos gravitacionais atuantes em condições confinadas e não-confinadas. $O$ roteiro recomendado concilia a otimização do percurso com a continuidade transicional de cada um dos tratos de fácies postulados.

Palavras-chaves: Subgrupo Itararé, ressedimentação, guia de campo, Bacia do Paraná, Permiano, Permocarbonífero, geologia sedimentar.

INTRODUÇÃO O roteiro aqui apresentado está subordinado ao tema ressedimentação no Subgrupo Itararé. Limita-se, portanto, aos afloramentos que expõem, de maneira didática, fácies ressedimentadas. Como conseqüência, a visão geral extraída desse conjunto de afloramentos não representa, globalmente, o trato de sistemas deposicionais desta unidade estratigráfica. O Subgrupo Itararé inclui, mesmo na área estudada, outros sistemas marinhos e costeiros, compostos por fácies que não se enquadram no tema aqui estudado.

Além do aspecto temático, a seleção de afloramentos obedeceu ao critério de representatividade das litofácies modeladas pela interpretação hidrodinâmica. Como o trato de fácies ressedimentadas constitui um espectro contínuo, cada afloramento se justifica pela exposição, de maneira típica e didática, de um elemento discreto dessa transição, ou seja, de cada íitofácies. Não obstante, a maioria dos afloramentos exibe uma associação de fácies de ressedimentação e, por vezes, engloba fácies de outros sistemas deposicionais. Nestes casos, as fácies associadas nem sempre representam adequadamente os elementos discretos referidos, podendo apresentar características transicionais entre duas litofácies. Assim, a comparação entre fácies semelhantes em afloramentos diferentes oferece um subsídio adicional para avaliação da continuidade transicional dos tratos de fácies postulados.

Embora este guia de campo inclua apenas sete afloramentos, é recomendada sua execução em dois dias sucessivos. Esta recomendação se justifica pela exuberância dos afloramentos, riqueza de detalhes e complexidade envolvida. O primeiro dia deve ser dedicado ao trato confinado de fácies, que inclui os afloramentos de 1 a 3 , visitados, necessariamente, nesta seqüência, posto que descrevem a evolução desta transição. Se houver necessidade de otimizar o percurso, recomenda-se iniciar pelo afloramento 3, da Rodovia dos Bandeirantes, visitando em seguida o 1, em Salto e, finalmente, o 2, em Porto Feliz. $\mathrm{O}$ segundo dia, abrangendo as fácies do trato não-confmado, deve ser iniciado pelo afloramento n. 4 , próximo a Itu, seguin- do a ordenação natural, que concilia a racionalidade geográfica de percurso com o direcionamento da transição de fácies.

TRATO NÃO-CONFINADO DE FÁCIES Afloramento 1 - Cruzamento para Salto O afloramento inicial deste guia situa-se no km 101 da rodovia estadual SP308, Rodovia do Açúcar, a cerca de $300 \mathrm{~m}$ da ponte sobre o Rio Tietê, no cruzamento com a rodovia SP-79 (Fig. 1).

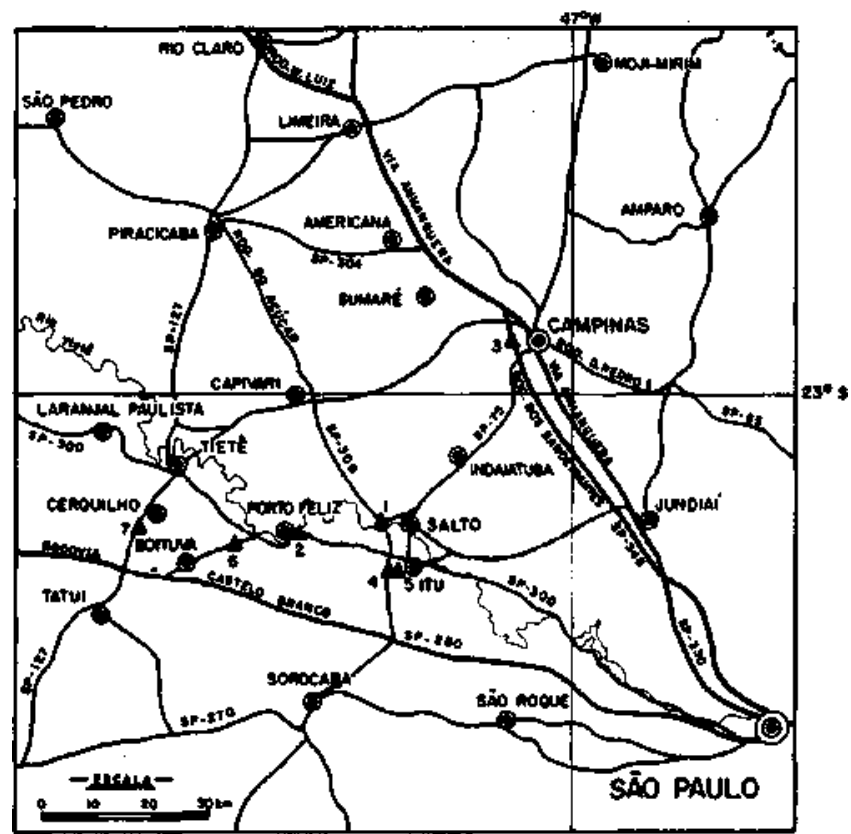

figurall - Mapa da região de Porto Feliz (SP) com a localização dos afloramentos (1 a 7)

Figure 1-Mapofthe Porto Feliz (SP) region with the location of outcrops (1 to 7)

\footnotetext{
* Departamento de Geologia Sedimentar, Instituto de Geociências e Ciências Exatas, UNESP, Campus Rio Claro, Caixa Postal 178, CEP 13500-970, Rio Claro, SP, Brasil

** Departamento de Geologia, Centro Politécnico, Universidade do Vale do Rio dos Sinos, Caixa Postal 275, CEP 93020-000, São Leopoldo, RS, Brasil

*** Ex-bolsista de Iniciação Científica da FAPESP - Processo 88/1968-5
} 
Suas dimensões atingem cerca de $20 \mathrm{~m}$ de largura por $4 \mathrm{~m}$ de altura, exibindo, como aspecto relevante, um canal escavado em arenitos e preenchido por diamictitos de ressedimentação (Fig. 2). Abaixo da superfície do canal acha-se exposta uma seqüência constituída, da base para o topo, de ritmitos várvicos (fácies $\mathrm{Fl}$ ), diamictitos organizados (fácies Dms) e arenitos estratificados. Acima da superfície de escavação assentam-se siltitos argilosos, os quais associam-se, no canal escavado, aos diamictitos de ressedimentação (fácies Dmm). Dentre todas estas fácies, apenas estes últimos diamictitos apresentam aspectos consistentes de ressedimentação e características ideais para um guia de campo.

O preenchimento do canal escavado iniciou-se com a decantação de finos (lamito maciço) com seixos pingados, da fácies Fmd (Foto 1), caracterizando um interregno entre sua escavação e posterior assoreamento subaquoso. Este assoreamento é completado pela deposição de diamictitos maciços com seixos centimétricos suportados pela matriz de composição lamítica. A inexistência de imbricação dos seixos, aliada à ausência de estratificação, caracteriza a fácies Dmm (Foto 2) e a Litofácies Diamictitos Desorganizados

O processo sedimentar inferido relaciona-se com fluxos de detritos de viscosidade intermediária, ocorridos em episódios discretos, sucessivos e de elevada intensidade energética. Como decorrência, os diferentes bancos de diamictitos foram deformados por diapirismo dos lamitos associados (Foto 3), conferindo-lhes uma geometria aparentemente sigmóide. Este diapirismo atesta a deposição subaquosa de ambas as fácies.

Constituído por bancos decimétricos a métricos, os arenitos subjacentes ao canal são de granulação fina a média, por vezes grossa, apresentando gradação normal e granodecrescência ascendente. As estruturas sedimentares mais abundantes são estratificações plano-paralelas horizontais na base dos bancos e cruzadas planares no topo (Foto 4), caracterizando-se, assim, como depósitos de processos tracionais em águas rasas, provavelmente associados a um sistema costeiro.

Estes bancos de arenito assentam-se sobre diamictitos com seixos polimíticos de dimensões centimétricas, suportados por matriz de natureza arenosa. Ao contrário do anterior, este diamictito já evidencia um certo grau de organização revelado por um incipiente acamamento, gradação inverso-normal e imbricação de seixos no plano horizontal. Esta sutil organização evidencia a deposição por um fluxo gravitacional, na transição de laminar coesivo para turbulento. Assim, fluxos de detritos e/ou correntes de turbidez de alta concentração podem ser inferidos como processos deposicionais dos diamictitos organizados (Pickering et al. 1986).

Finalmente, os siltitos argilosos que se sobrepõem aos depósitos que preencheram o canal escavado, apresentam-se com geometria lenticular, exibindo uma sutil gradação e, por vezes, deformações plásticas. Sua origem é atribuída a lobos de suspensão.

Afloramento 2 - Gruta de Porto Feliz Compondo um agradável recanto no parque da cidade no centro de Porto Feliz, este afloramento é representado por um paredão subvertical, à margem esquerda do Rio Tietê. Este recanto serviu de porto para as históricas monções que de Porto Feliz partiam rumo ao sertão brasileiro. As dimensões do paredão superam os $100 \mathrm{~m}$ de extensão e $20 \mathrm{~m}$ de altura, expondo diversos bancos ou lentes da Litofácies Arenitos Estratificados. Estes arenitos assentam-se sobre um paleorrelevo escavado em arenito lamítico seixoso (Fig. 3). Em razão da disposição íngrime do afloramento, somente os bancos ou camadas inferiores puderam ser descritos com o detalhe pretendido.

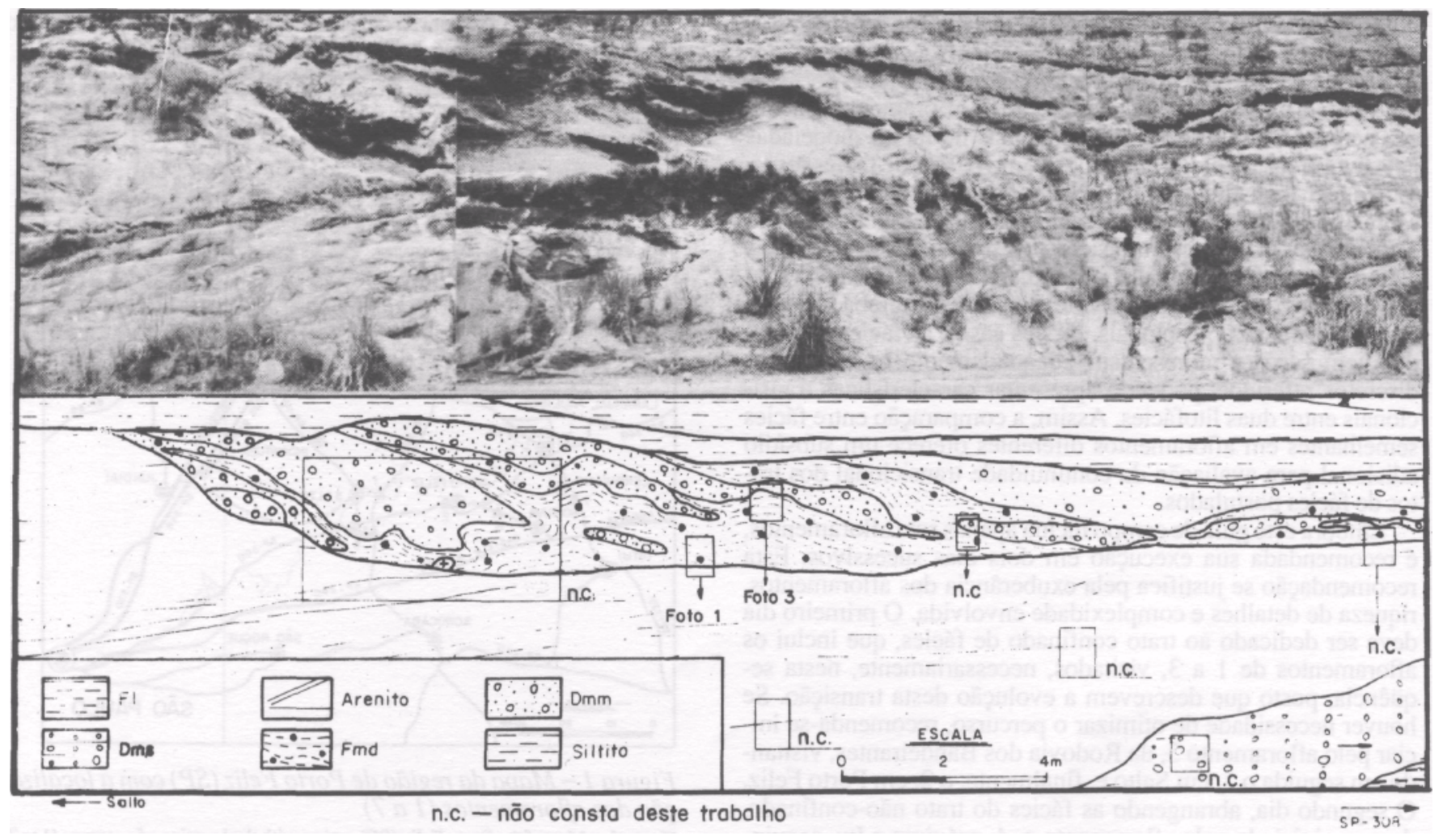

Figura 2 - Seção esquemática do afloramento 1, entroncamento para Salto pela rodovia SP-308 (km 101). O aspecto relevante relaciona-se com a feição de escavação de um canal, observado em corte diagonal, e seu preenchimento por diamictitos de ressedimentação (fáceis Dmm)

Figure 2 - Schematic section of outcrop 1 - SP-308, Açúcar Highway (Km. 101). The main aspect is one scoured channel (in a diagonal view) filled up by resedimented diamictites (facies Dmm) 


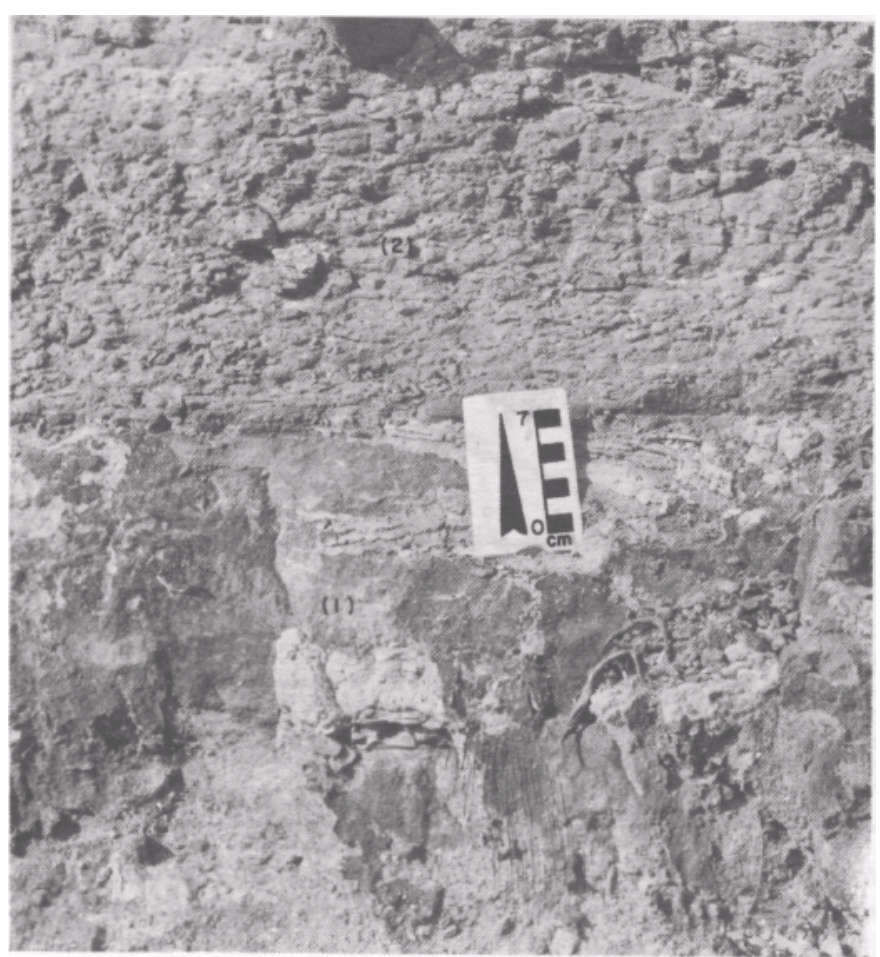

Foro 7 - Afloramento 1 (cruzamento para Salto). Detalhe da base do canal escavado em arenitos (1). Os lamitos (2) sobrepostos apresentam seixos pingados

Photo 1 - Outcrop 1 (Açúcar Highway, km. 101, junction to Salto). Detail of the channel's base scoured in sandstone (1). The superposed mudstones (2) show dropstones

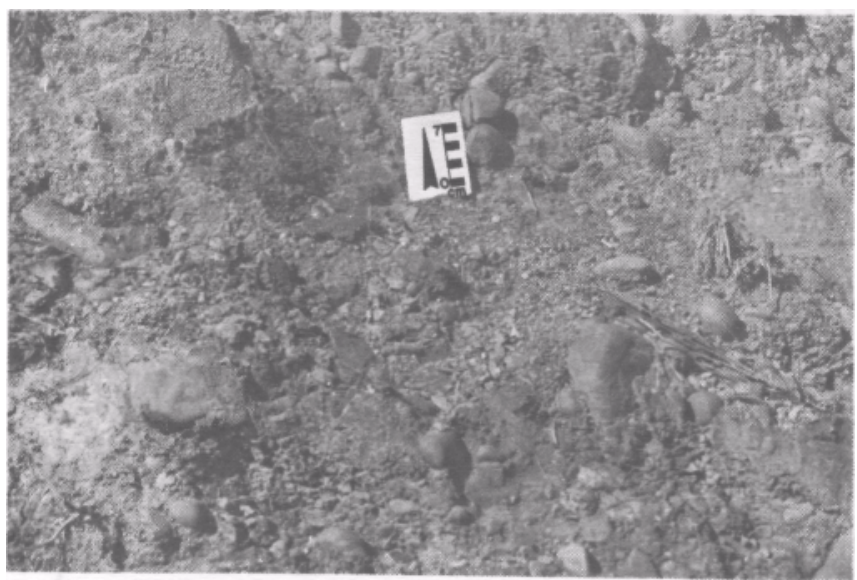

Foto 2 - Detalhe dos diamictitos desorganizados que preenchem o canal do afloramento 1. Observar o caráter maciço e ausência de imbricação ou gradação

Photo 2 - Detail of disorganized diamictites that fill the scoured channel of outcrop 1 . Note the massive character and absence of imbrication or grading

As camadas de arenito se sucedem ritmicamente, superpondo-se em onlap (Foto 5) e preenchendo o que aparenta ser um canal de dimensões superiores ao do afloramento. A seção colunar da figura 4 descreve detalhadamente as duas camadas basais (camadas 2 e 3 ) que se assentam sobre a superfície resultante do escavamento do canal. Como características persistentes em todas as camadas, os arenitos são de gramüação fina a grossa, com notável gradação normal e base erosiva.

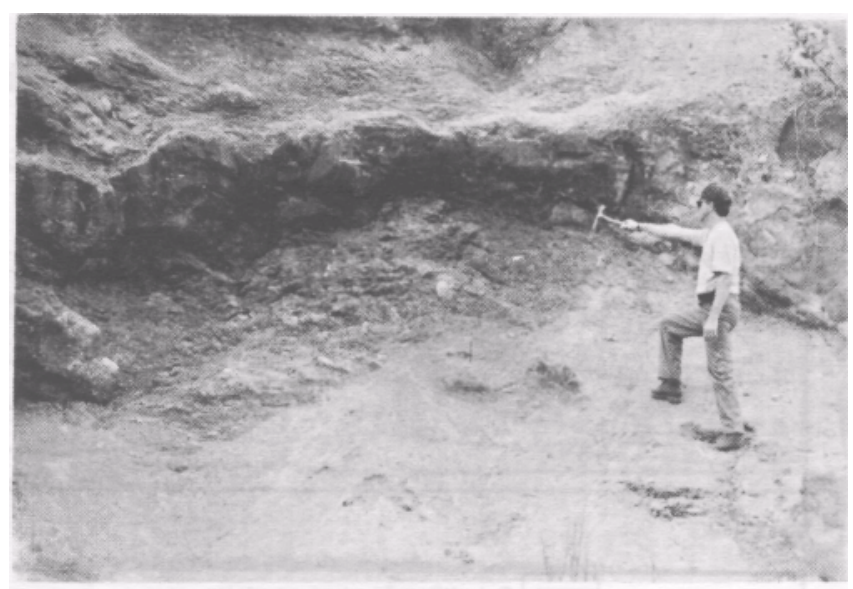

Foto 3 - Detalhe do diapirismo dos lamitos (fáceis $\mathrm{Fl}$ ) no contato com os diamictitos desorganizados (fáceis Dmm) no afloramento 1

Photo 3 - Detail of the mudstone diapirism (facies Fl) at the contact with the disorganized diamictites (facies Dmm). Outcrop 1

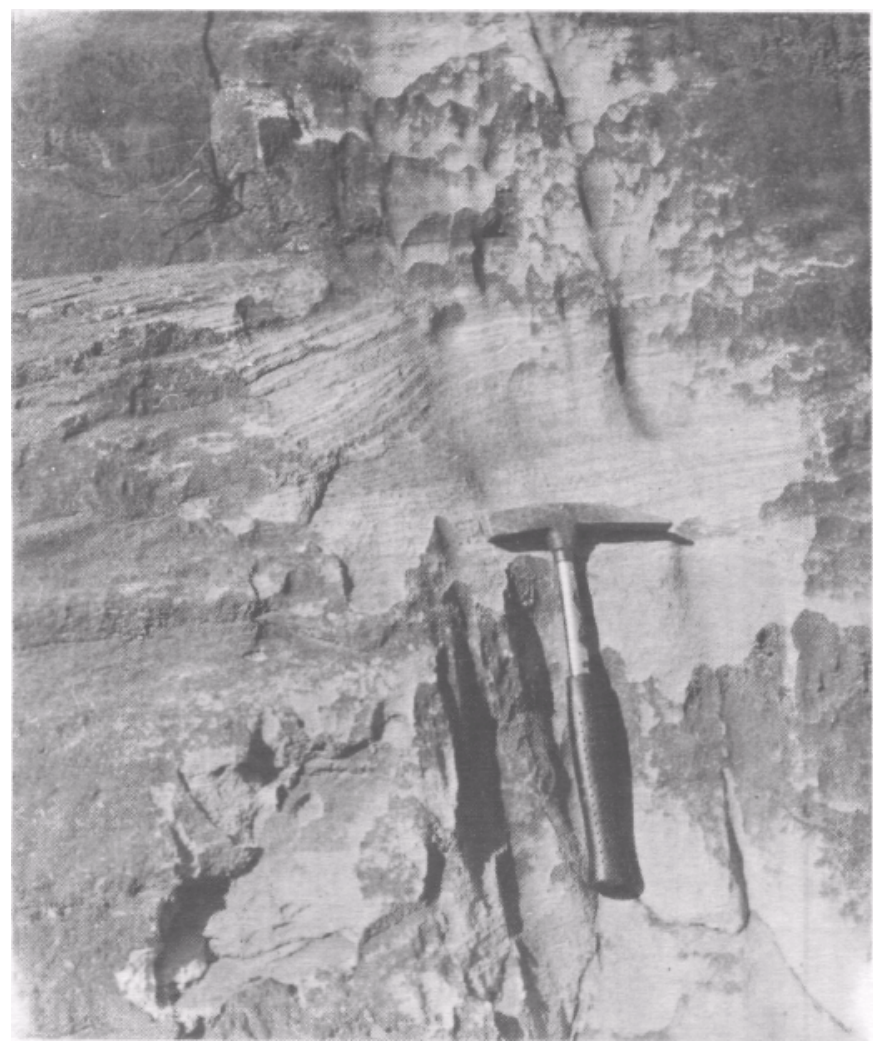

Figura 4 -Afloramento 2 (Gruta de Porto Feliz). Detalhe dos bancos arenosos (fáceis Sgr) assentados sobre o arenito lamítico seixoso (fáceis $S m d$ )

Figure 4 - Outcrop 2 (Porto Feliz Grotto). Detail of sandy banks (facies Sgr) disposed on pebble muddy sandstone (facies Smd)

Possuem uma ordenada sucessão vertical de estruturas sedimentares que, da base para o topo, incluem: caráter maciço, estratificação planorizontal, cruzadas planares ou acanaladas, cruzadas cavalgantes e laminação horizontal (Foto 6). Porém, cada camada apresenta seu arranjo específico, ora iniciando com aspecto maciço, ora com estratificação planorizontal, ora com cruzadas planares, seqüenciando-se na ordenação referida. Essa mesma ordenação de estruturas sedimentares é, da 


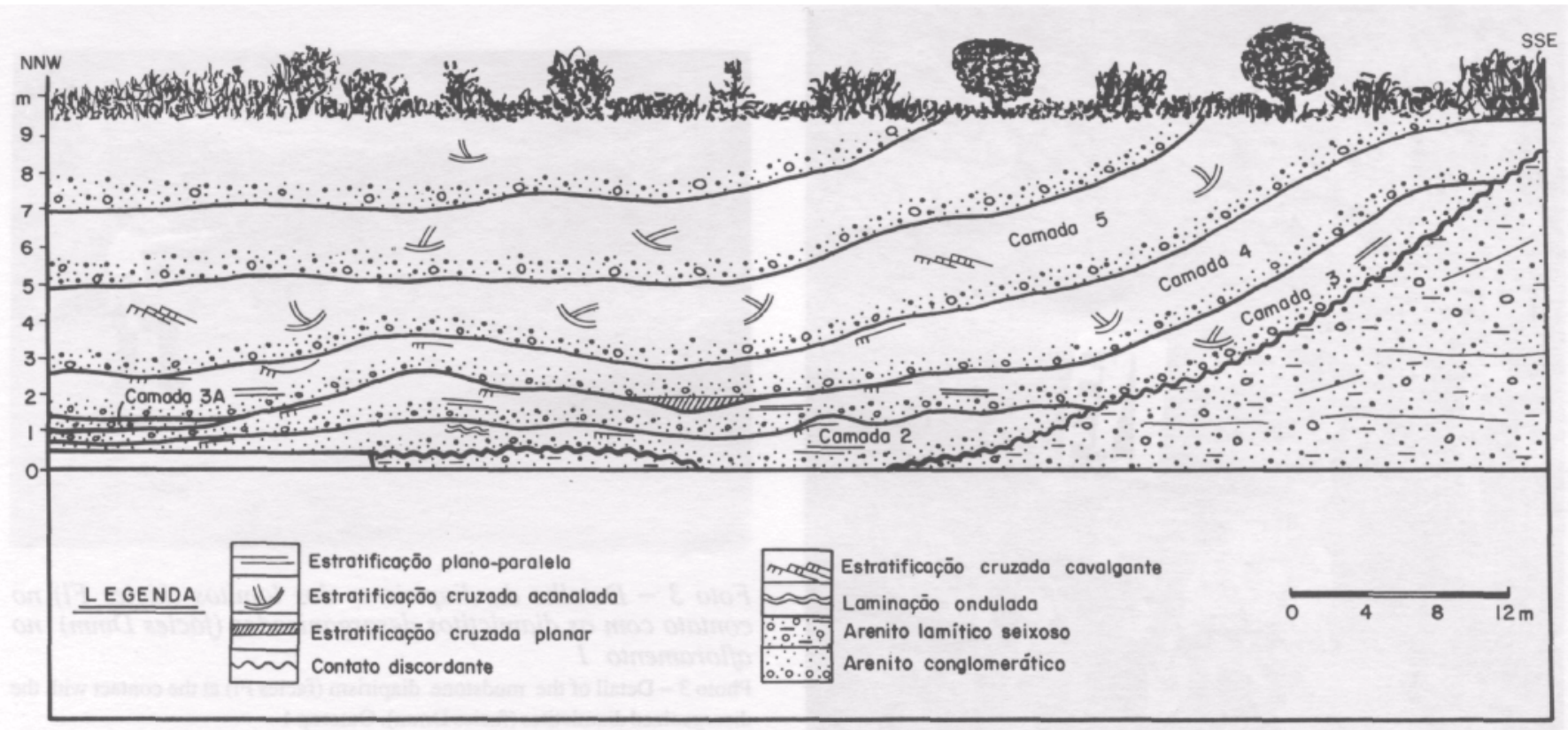

Figura 3 - Seção esquemáíica do afloramento 2 (Gruta de Porto Feliz). Bancos e lentes de arenito com gradação vertical de textura e estruturas sedimentares (fáceis $\mathrm{Sg}$ ) dispostos sobre um paleo-relevo escavado em arenito lamítico seixoso (fáceis Smd). Observar as relações de onlap

Figure 3 - Schematic section of outcrop 2 - Porto Feliz Grotto. Sandstone banks and lenses with vertical grading of texture and sedimentary structures (facies Sg). The banks and lenses are disposed on a paleorelief scoured in pebble muddy sandstone (facies Smd). Note the onlap relationships

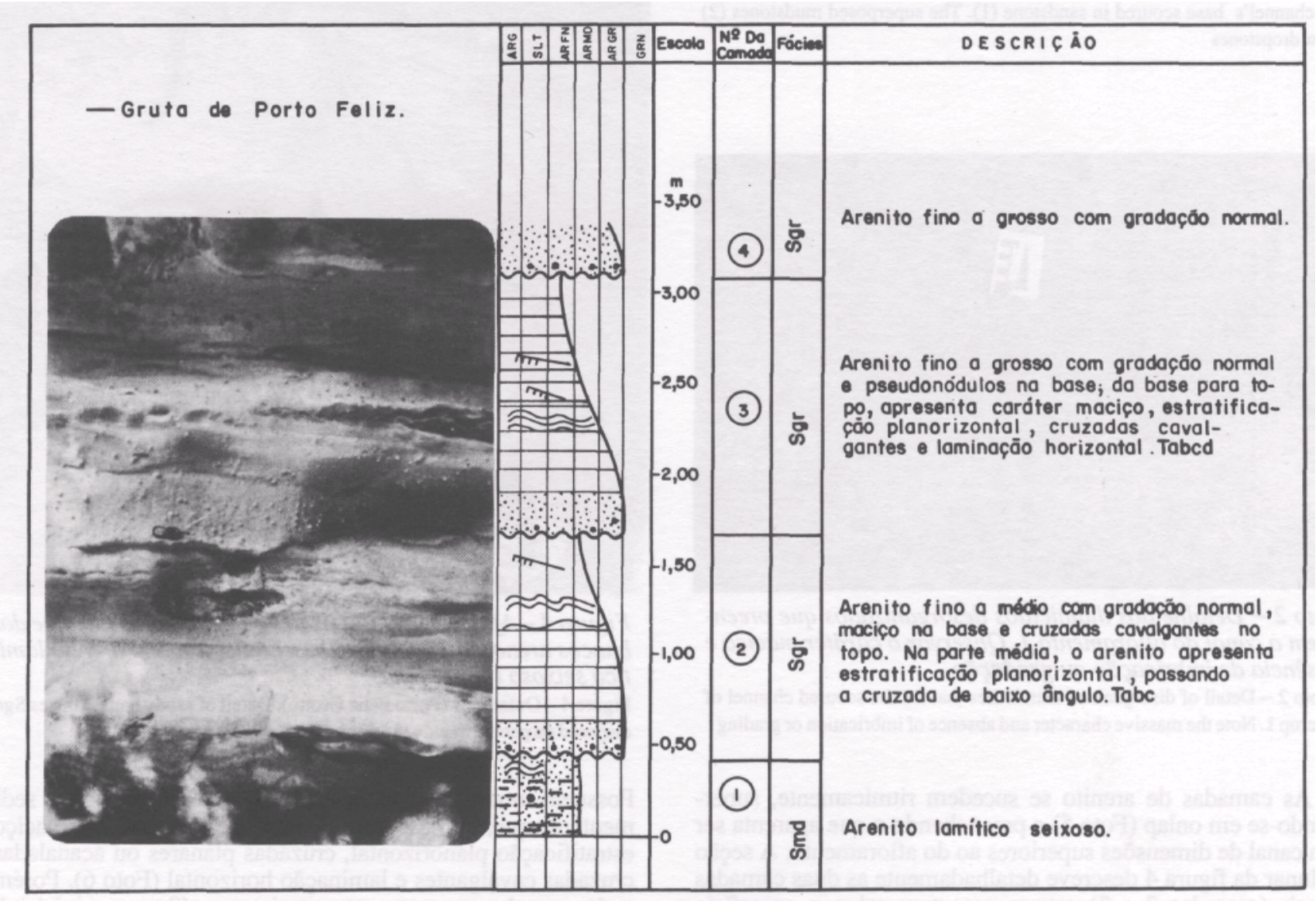

Figura 4 - Afloramento 2 (Gruta de Porto Feliz). Detalhe dos bancos arenosos (fáceis Sgr) assentados sobre o arenito lamítico seixoso (fáceis $\mathrm{Smd}$ )

Figure 4 - Outcrop 2 (Porto Feliz Grotto). Detail of sandy banks (facies Sgr) disposed on pebble muddy sandstone (facies Smd) 
mesma forma, observada lateralmente ao longo das camadas, particularmente com as estruturas de menor energia, como as estratificações cruzadas cavalgantes. No sentido das inferidas paleocorrentes, as cruzadas cavalgantes passam do tipo A para o tipo B (Jopling \& Walker 1968) e, finalmente, para laminação ondulada ou sinusoidal (Foto 7). Na foto 7, são observáveis, ainda, o desenvolvimento de pseudonódulos nos horizontes maciços de cada camada. $\mathrm{O}$ empilhamento dessa seqüência arenosa se faz por imbricação dos depósitos.

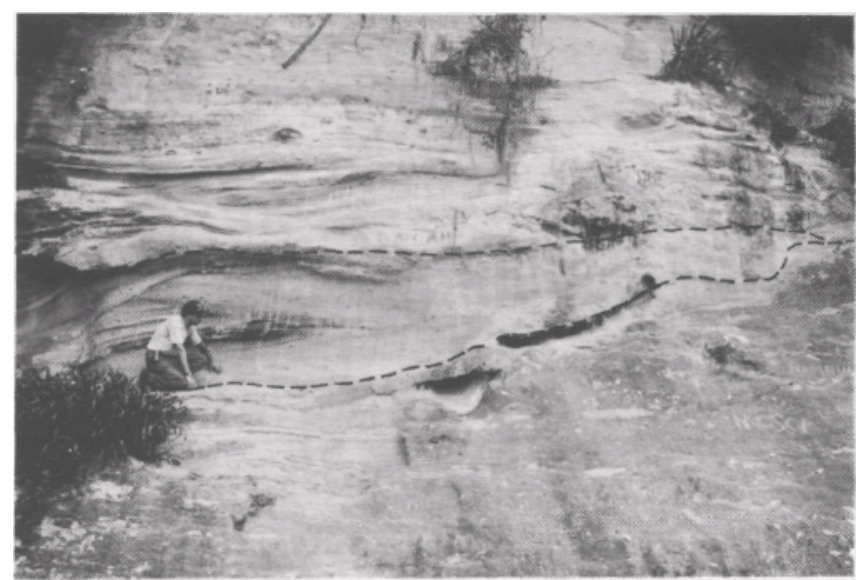

Foío 5 - Afloramento 2 (Gruta de Porto Feliz). Acunhamento em onlap das camadas de arenito gradacional (fáceis Sgr) contra o paleo-relevo escavado no arenito lamítico seixoso (fáceis Smd)

Photo 5 - Outcrop 2 (Porto Feliz Grotto) - Gradational sandstone beds (facies Sgr) onlap wedge out against the paleorelief scoured in pebble muddy sandstone (facies Smd)

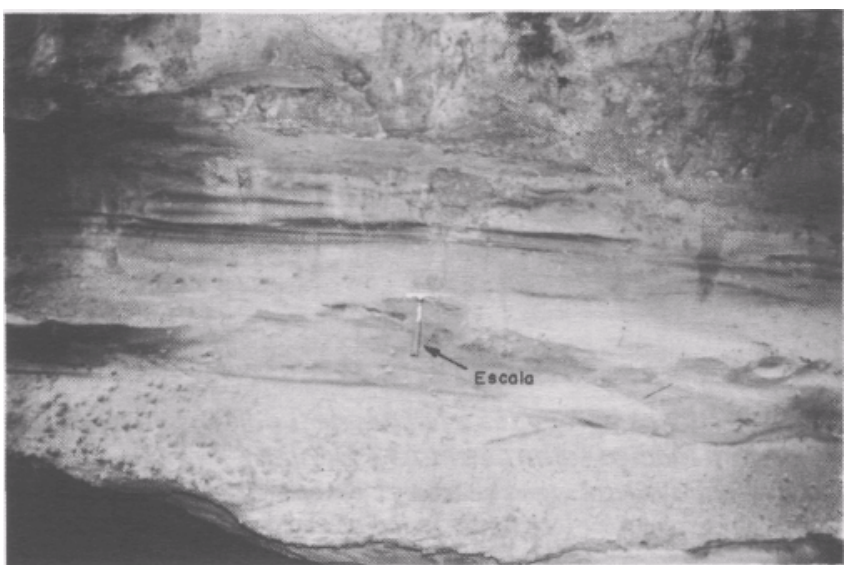

Foto 6 - Bancos de arenitos com gradação normal, caráter maciço na base e, no topo, laminação planorizontal, localmente ondulada (afloramento 2 - Gruta de Porto Feliz) Photo 6 - Banks of sandstones with normal grading, massive character at the base and, at the top, parallel horizontal lamination, wavy locally (outcrop 2 Porto Feliz Grotto)

Os bancos, camadas ou lentes arenosas deste afloramento são aqui interpretados como depósitos de eventos episódicos de natureza subaquosa e turbulenta. Em cada evento, o domínio confinado é palco de correntes de turbidez de alta concentração que, transportando uma população de clastos previamente selecionada pela própria intensidade da turbulência, produzem um turbidito essencialmente arenoso. Nos termos do modelo de Bouma (1962), configuram-se como Tabc, Tbc e Tbcd.

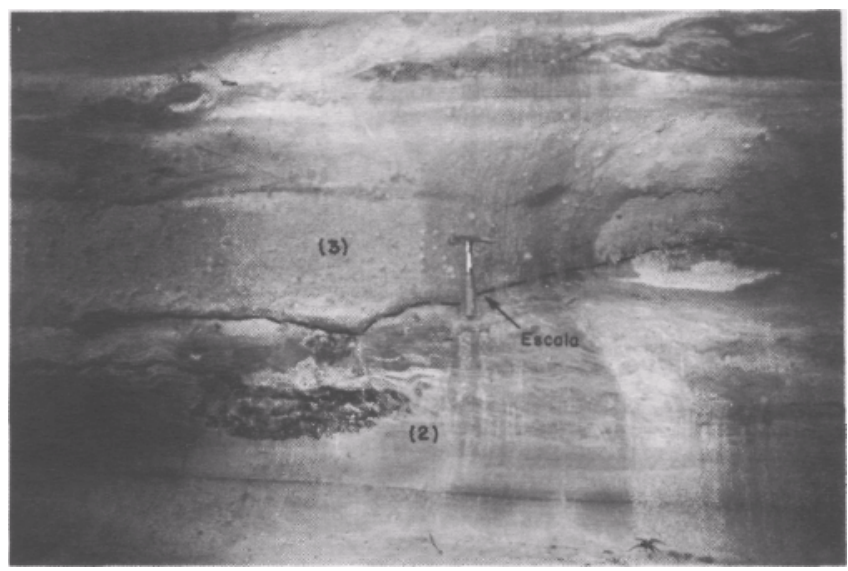

Foto 7 - Contato entre a camada 2, com laminação cavalgante sinusoidal, e a base da camada 3 com pseudonódulos (afloramento 2 - Gruta de Porto Feliz)

Photo 7 - Contact between the bed 2, with sinusoidal climbing ripple crosslamination, and the base of the bed 3, with pseudo-nodules (outcrop 2 - Porto Feliz Grotto)

Afloramento 3 - Viaduto Dunlop Esse afloramento localiza-se no km 94,5 da rodovia dos Bandeirantes, SP-348, junto ao viaduto Dunlop (Fig. 1), estando exposto em dois cortes de ambos os lados da rodovia. Este afloramento possui uma extensão superior a $150 \mathrm{~m}$ e altura de, aproximadamente, $20 \mathrm{~m}$. A figura 5 apresenta um painel geral do corte leste da rodovia, sentido São Paulo - interior. Orientando-se pelo referido painel, o afloramento expõe em 1 , arenitos acamados, de granulação média, bem selecionados, com estratificação cruzada acanalada, eventual gradação normal e bandas maciças. Caminhando no sentido de 1 para 2 , as estruturas primárias vão se descaracterizando e, gradativamente, o arenito vai se tornando maciço. Feições convolutas derivadas de fluidização e fluxo viscoso vão se fazendo presentes (Foto 8), paralelamente à incorporação de blocos não fluidizados do próprio arenito (Foto 9). Galhas de argila se tornam abundantes.

A partir da área central do afloramento (2), os arenitos se tornam totalmente maciços (fácies $\mathrm{Sm}$ ), tendo sua homogeneidade interrompida apenas por superfícies irregulares e descontínuas que se assemelham a megaestrutura de escape d'água. Uma hipótese plausível para origem dessas superfícies seria a preservação, como feições palimpsésticas, dos acamamentos primários. Outra feição notória e bastante freqüente nesta fácies é a estrutura de escape de água, composta por um feixe vertical ou subvertical de superfícies $\mathrm{Z}$ convergentes (Foto 10).

Completando a descrição desse afloramento, em 3, no extremo norte do afloramento, a fácies maciça apresenta uma aparente orientação vertical das supostas linhas de fluxos, denotando uma fluidização mais intensa. Esta feição encontrase presente em ambos os lados da rodovia.

A interpretação postulada na modelagem hidrodinâmica atribui a origem da Litofácies Arenitos Maciços, à fluidização, por escape de água, nos momentos finais da deposição de arenitos por correntes de turbidez de concentração intermediária. Esta fluidização seria decorrente da brusca desaceleração do fluxo na passagem de condições confinadas para nãoconfmadas e conseqüente rápida decantação de clastos. $\mathrm{O}$ escape da água, abundantemente aprisionada nos vazios intersticiais, provocaria o fluxo de acomodação. 

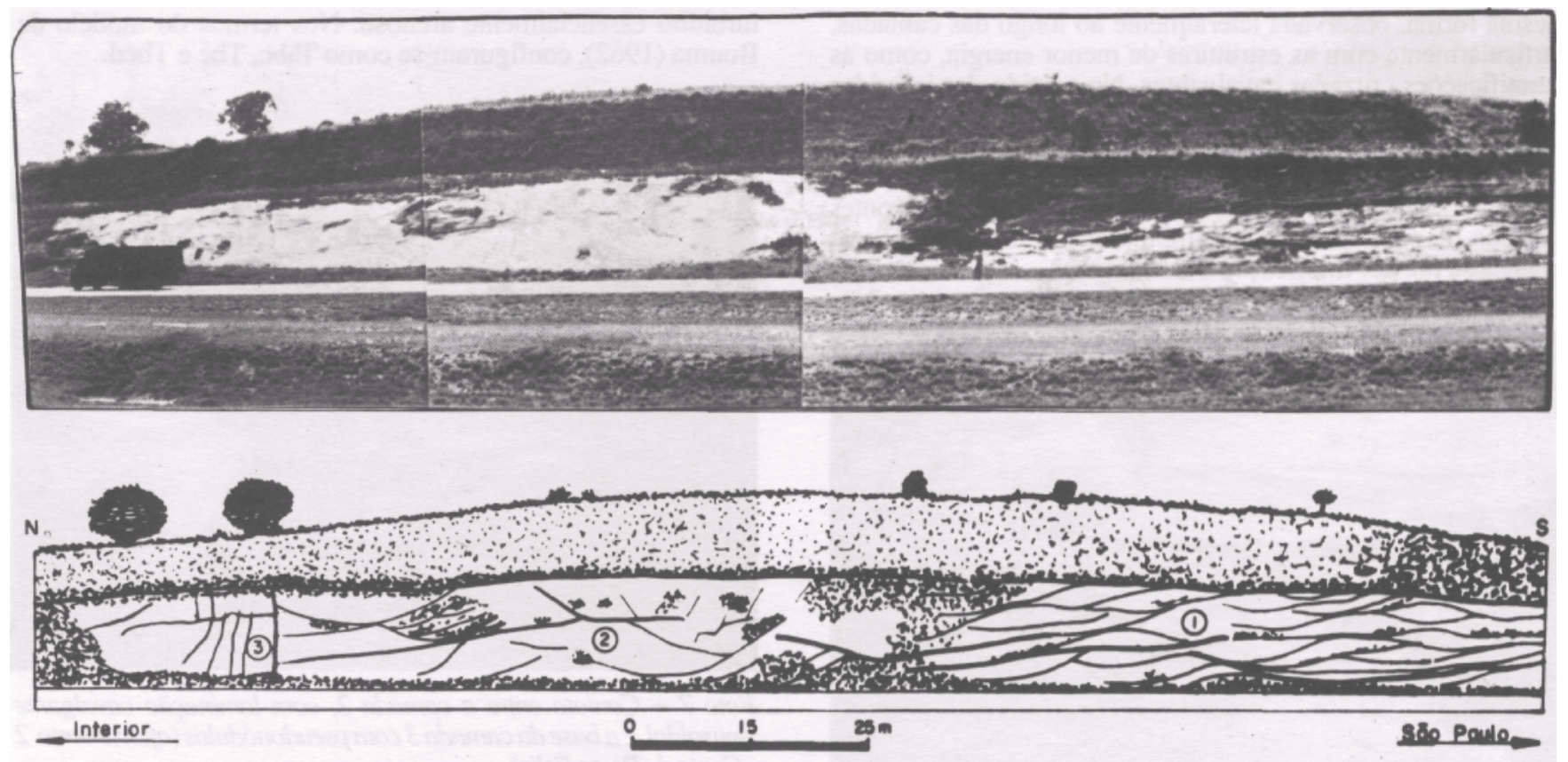

Figura 5 - Visão geral e seção esquemática do afloramento 3 (viaduto Dunlop), $\mathrm{km}$ 94,5 da rodovia dos Bandeirantes. Em (1) arenitos com estratificações cruzadas acanaladas (fáceis St), passando gradualmente em (2) e mais intensamente em (3) para arenitos maciços (fáceis Sm)

Figure 5 - General view and schematic section of outcrop 3 (Dunlop viaduct), Bandeirantes Highway, km 94,5. Number 1 means trough cross-bedding sandstones (fáceis St), gradually changing (2) and more intensely (3) to massive sandstones (fáceis Sm)

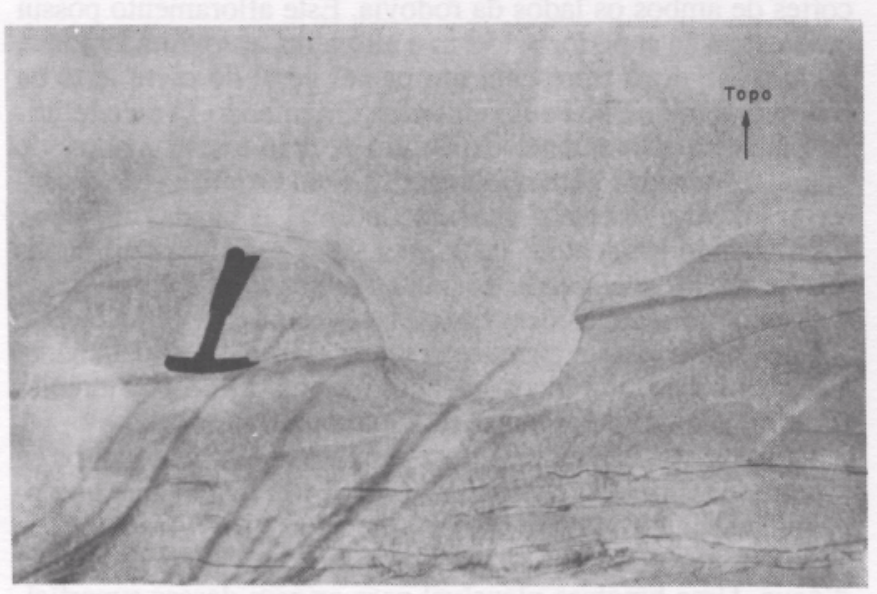

Foto 8 - Feições derivadas de diferentes intensidades de fluidização (afloramento 3 - Dunlop)

Photo 8 - Features originated from different intensity of fluidization (outcrop 3 - Dunlop viaduct)

TRATO NÃO-CONFINADO DE FACIES Afloramento 4 - Rodovia de Açúcar Este afloramento situa-se no km 93,5 da Rodovia do Açúcar, SP - 308, no lado direito de quem se dirige de Sorocaba para Piracicaba (Fig. 1). Dista aproximadamente $2 \mathrm{~km}$ da Pedreira de Itu, expondo sedimentos da mesma seqüência estratigráfica. Sua exposição foi provocada pela recente duplicação da rodovia Sorocaba-Campinas que produziu um corte de estrada de extensão superior a $80 \mathrm{~m}$ por, um máximo, 10 de altura.

Neste roteiro, o afloramento 4 representa a Litofácies Ritmitos Gradados, cuja ritmicidade é produzida pela alternância de arenitos gradados com estruturas tracionais da fácies Srg com níveis milimétricos da fácies de finos $(\mathrm{Fl})$ (Foto 11). Os

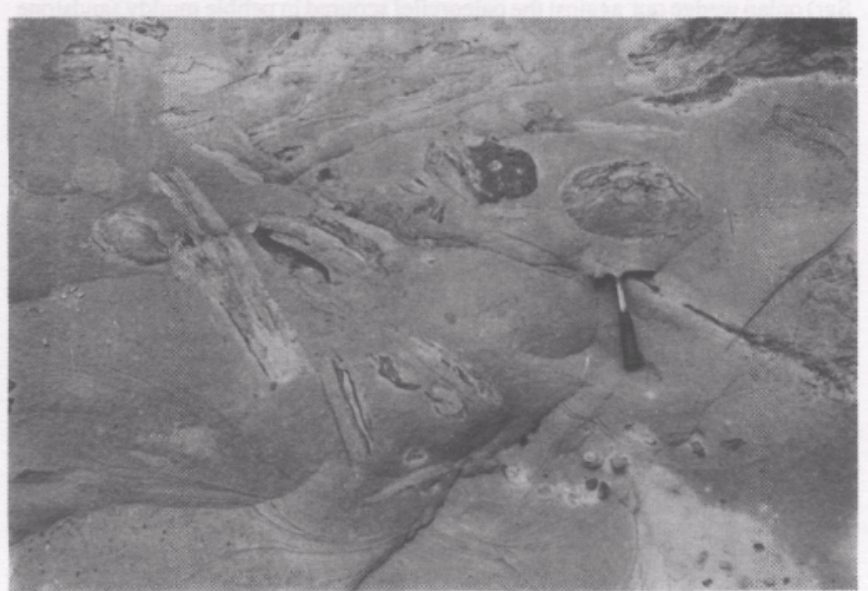

Foto 9 - Blocos agregados e feições de fluidização associadas no arenito maciço (afloramento 3 - Dunlop)

Photo 9 - Association of aggregated rocky bloks and features from fluidization in the massive sandstone (outcrop 3 - Dunlop viaduct)

arenitos, que se apresentam em camadas centimétricas a decimétricas, predominam na seqüência exposta, mostrando belíssimos exemplos de estruturas cruzadas cavalgantes do tipo $\mathrm{B}$, ilustradas em detalhe na foto 12 . A ritmicidade dessa litofácies é decorrência da alternância de processos tracionais, que modelam as formas de leito, seguidos da decantação de finos (Foto 13). O acamamento ondulado deriva da preservação, por decantação, das formas tracionais do leito arenoso.

Na parte superior da seqüência exposta, as intercalações arenosas são mais raras, de modo que, quando presentes, assentam-se em espessos pacotes de sedimentos pelíticos. Por sobrecarga, são produzidas estruturas do tipo balls \& pillows e lutocinese. 


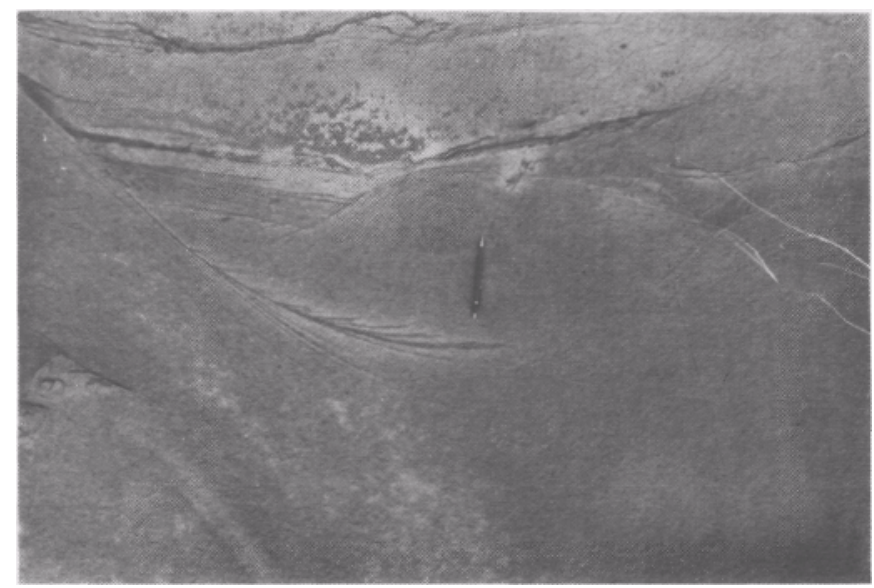

Foto 10 - Estrutura de escape de água em arenito maciço fluidizado (afloramento 3 - Dunlop)

Photo 10 - Dewatenng structure in fluidized massive sandstone (outcrop 3 Dunlop viaduct)

Na modelagem hidrodinâmica proposta, esta litofácies é interpretada como depósitos de correntes de turbidez episódicas, de baixa concentração. Em cada evento turbulento, o corpo principal das correntes forneceria o suprimento de areias, ao mesmo tempo em que seu efeito tracional modelaria o substrato arenoso. A decantação dos finos, mantidos em suspensão nas caudas de cada evento, emprestaria o caráter rítmico desta litofácies, que corresponde no modelo de Bouma (1962) aos horizontes c e d.

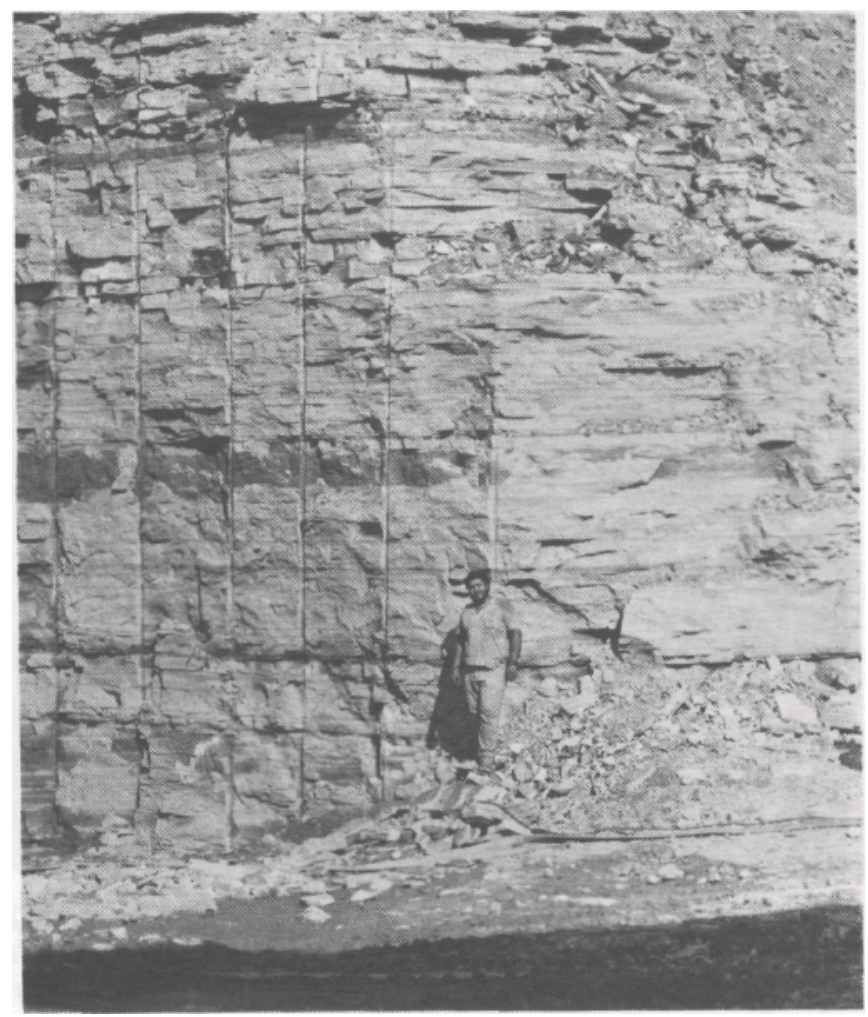

Foto 11 - Visão parcial do corte do afloramento 4 (SP-308, rodovia do Açúcar, $\mathrm{km}$ 93,5), composto por ritmitos gradados Photo 11 - Partial view of the outcrop 4 (SP-308, Açúcar Highway, $k m$ 93.5) composed by graded rhy thmites

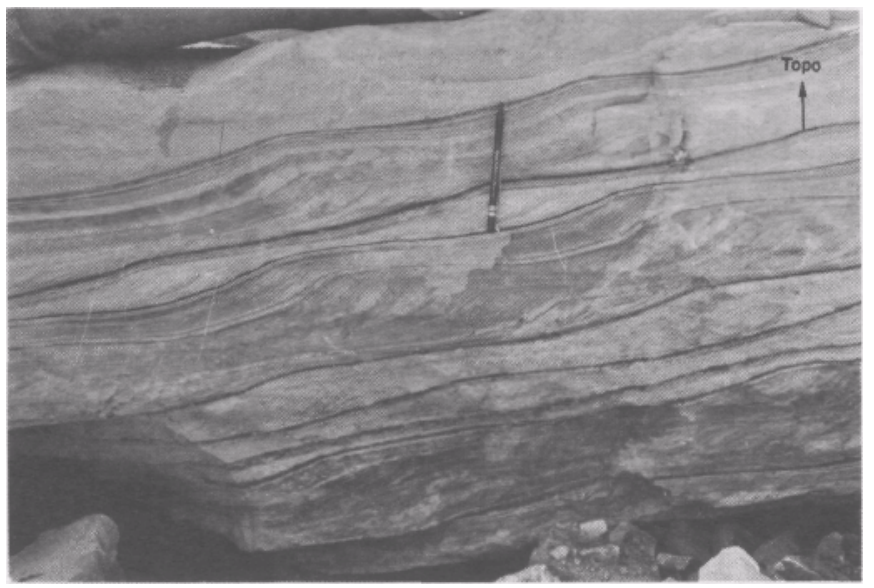

Foto 12 - Detalhe da fáceis de ritmitos gradados com estruturas tracionais. Laminações cruzadas cavalgantes do tipo B compondo o acamamento ondulado (afloramento 4 - Rodovia do Açúcar)

Photo 12 - Detail of the facies graded rhy thmites with tractive structures. Type B climbing ripple cross-lamination forming the wavy bedding (outcrop 4 - Açúcar Highway)

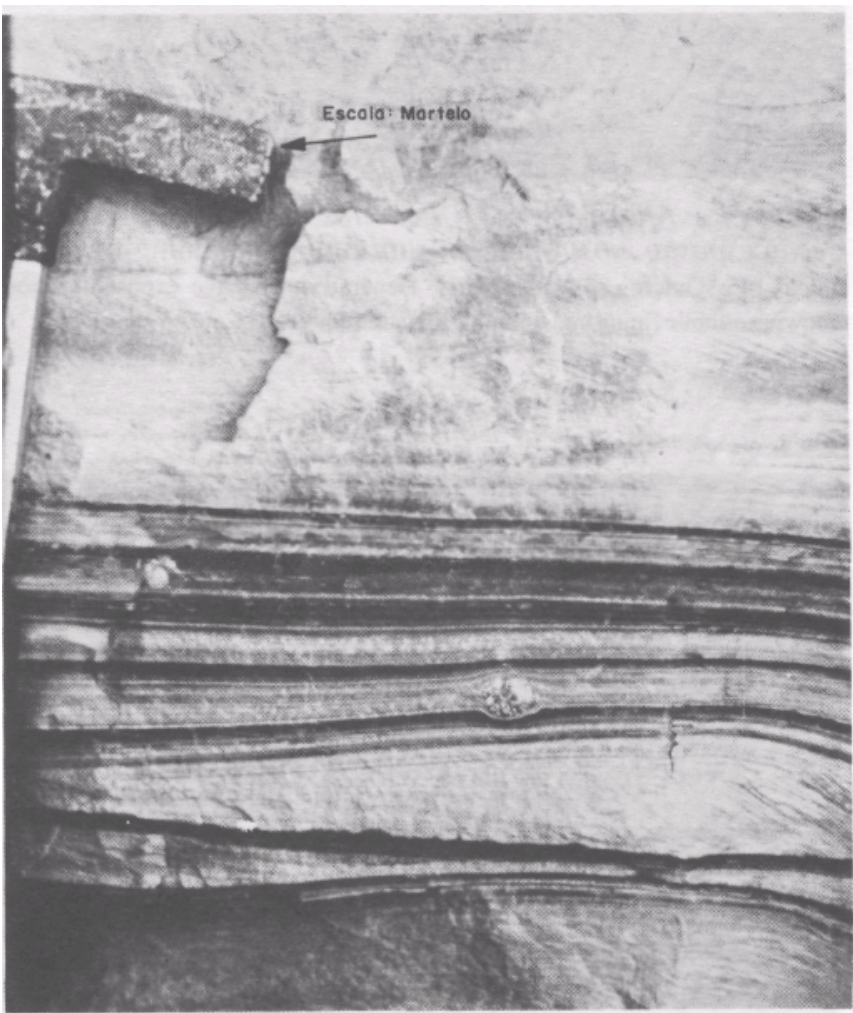

Foto 13 -A ritmicidade da facies ritmitos gradados deriva da alternância de processos tracionais que modelam as formas de leito, seguido de decantação de finos que preservam as formas de leito modeladas (afloramento 4 - Rodovia do Açúcar) Photo 13 - The rhythmic character of the facies graded rhythmites comes from the alternation of the tractive processes that shape the bed forms and the decantation of the fines that preserve the modeled bed forms (outcrop 4 Açúcar Highway) 


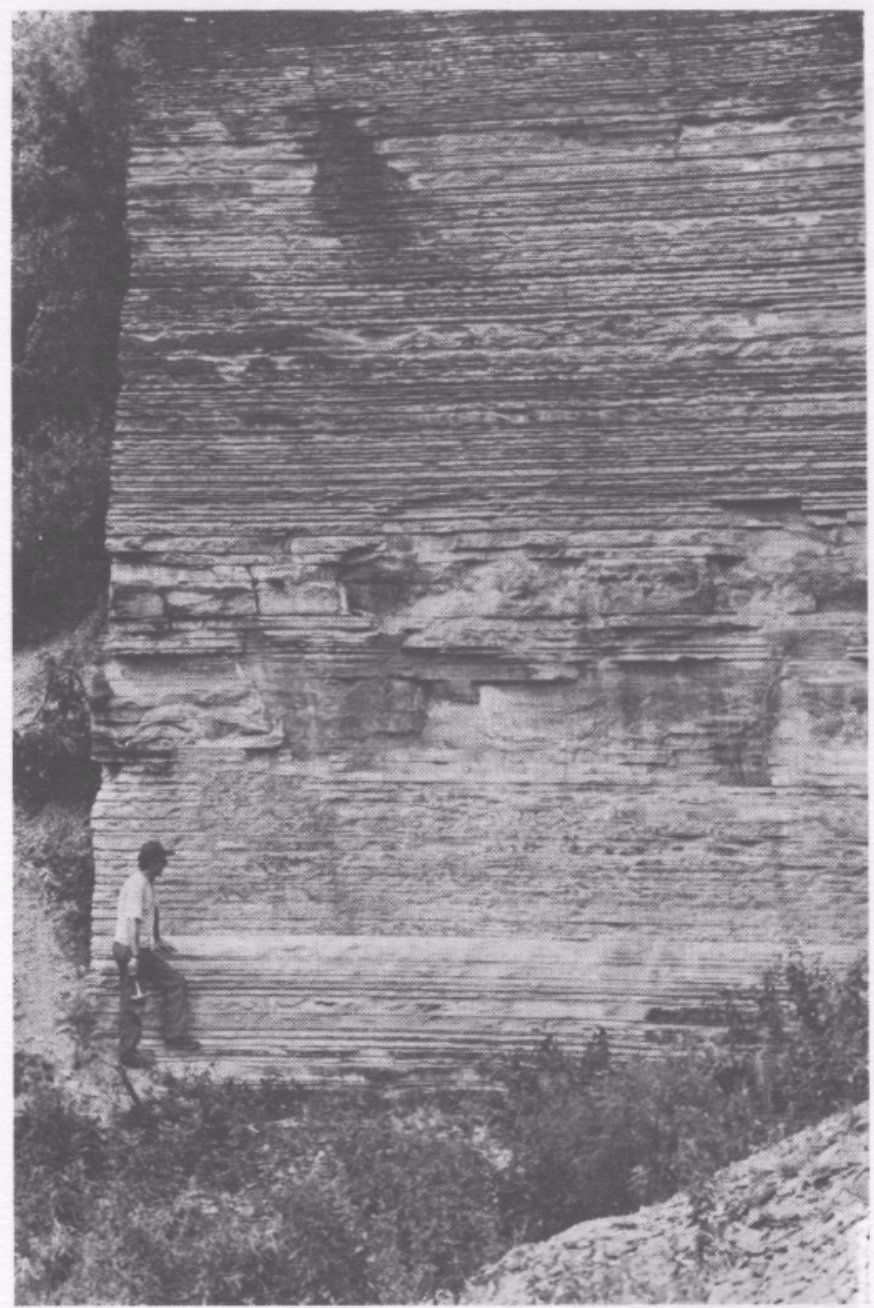

Foto 14 - Afloramento 5 - Pedreira de Itu. Visão geral da seção exposta, mostrando um sutil fining $e$ thinning-upward Photo 14 - Outcrop 5 - Itu Quarry. General view of the exposed section showing a subtle fining and thinning-upward sequence

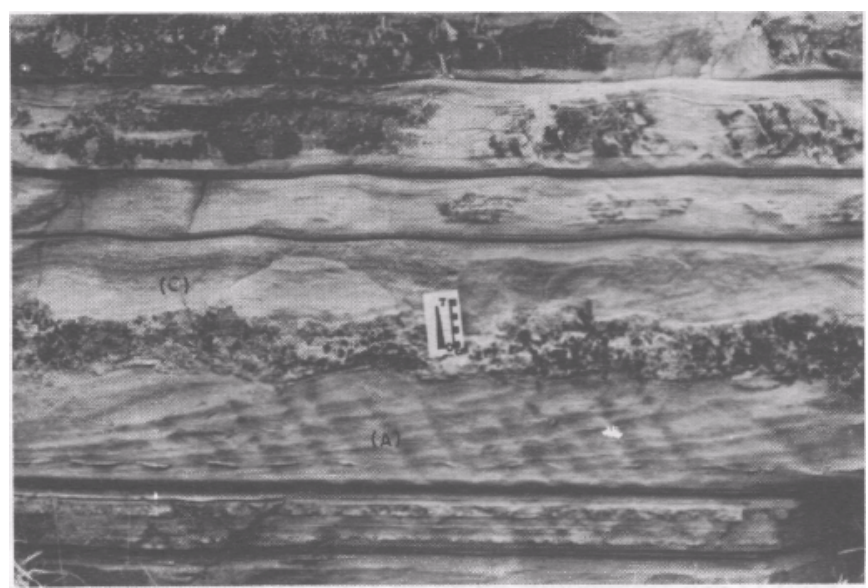

Foto 15 - Detalhe de um riímito gradado na pedreira de Itu(afloramento 5). Observar as evidentes indicações de processos tracionais. Laminações cruzadas cavalgantes do tipo A na base e sinusoidal (tipo C) no topo

Photo 15 - Detail of the graded rhythmite in the Itu Quarry (outcrop 5). Note the evident indication of tractive process. At the base an A type climbing ripple cross-lamination and a sinusoidal $\mathrm{C}$ type on the top
Afloramento 5 - Pedreira de Itu Este afloramento, tradicional em guias de campo sobre o Subgrupo Itararé no Estado de São Paulo, constitui-se num dos mais importantes patrimônios geológicos da Bacia do Paraná e uma das exposições que tem merecido maior atenção dos pesquisadores. Dentre os estudos geológicos ali realizados citam-se: Leonardos (1938), Ab'Saber (1948), Barbosa \& Almeida (1949), Mezzalira (1966, 1969), Rocha-Campos (1967, 1972), Rocha-Campos \& Sundaran (1981), Petri (1985), Fernandes et al.(1987). De um modo geral, a origem lacustre por decantação sazonal (varvas) tem prevalecido como consenso, embora a maioria desses autores façam referências a camadas marinhas e/ou processos gravitacionais.

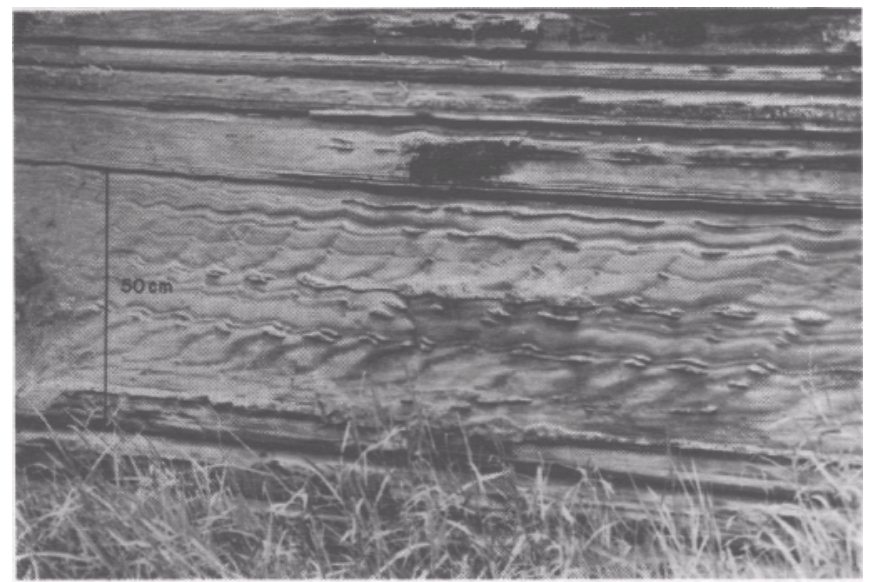

Foto 16 - Detalhe dos ritmitos gradados da pedreira de Itu (afloramento 5). Presença de acamamento wavy $e$ linsen $e$ laminações cruzadas cavalgantes evidenciando sua origem por processos tracionais

Photo 16 - Other detail of the graded rhythmite in the Itu Quarry (outcrop 5). Presence of wavy and linsen bedding and climbing ripple cross-lamination, evidencing its tractive process origin

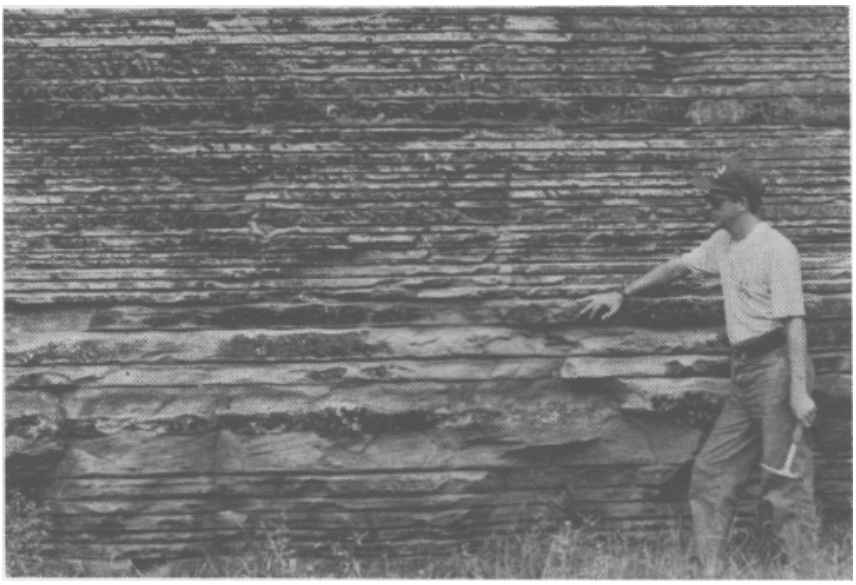

Foto 17 - Visão parcial da pedreira de Itu (afloramento 5), mostrando os dois tipos de ritmitos: ritmitos gradados (metade inferior da foto) depositados por processos tracionais derivados de suspensões e ritmitos várvicos (metade superior) depositados exclusivamente por decantação

Photo 17 - Partial view of Itu Quarry (outcrop 5), showing the two types of rhythmites: graded rhythmites (lower half part of the photo) deposited by tractive process derived from suspensions, and varved rhythmites (upper half part) deposited only by decantation 


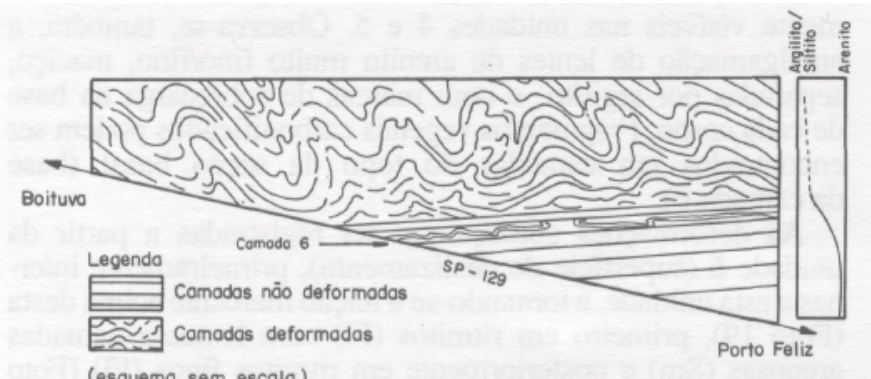

Figura 6 - Esquema do afloramento da SP-129 (Rodovia Vicente Palma), km 0,5. Destaque para a deformação da parte superior do afloramento sobre camadas não-deformadas (sem escala)

Figure 6 -Scheme of outcrop number 6 (Vicente Palma Highway), SP-129, km 0,5 . Prominence to the deformation of the upper parts of the outcrop lying on the undeformed lower beds (without scale)

Este afloramento situa-se nos arredores da cidade de Itú, com acesso pelo km 92,3 da Rodovia do Açúcar, SP - 308 e por estrada secundária proveniente da própria cidade de Itú. A pedreira, de onde são extraídas lajes para utilização como revestimento na construção civil, é composta de várias frentes de desmonte, algumas das quais abandonadas. A foto 14 ilustra a seção exposta; para a descrição foram utilizadas as exposições das várias frentes de desmonte. Com uma espessura total de $10 \mathrm{~m}$, a seção exposta eqüivale, estratigrafícamente, ao do afloramento 4. Contudo, a fácies Srg, que é dominante no referido afloramento, aqui se apresenta como intercalações erráticas, em siltitos e argilitos. $\mathrm{O}$ conjunto revela marcante diminuição da espessura das camadas arenosas em direção ao topo (thinning upward\}, acompanhada por uma sutil granodecrescência ascendente (fining upward).

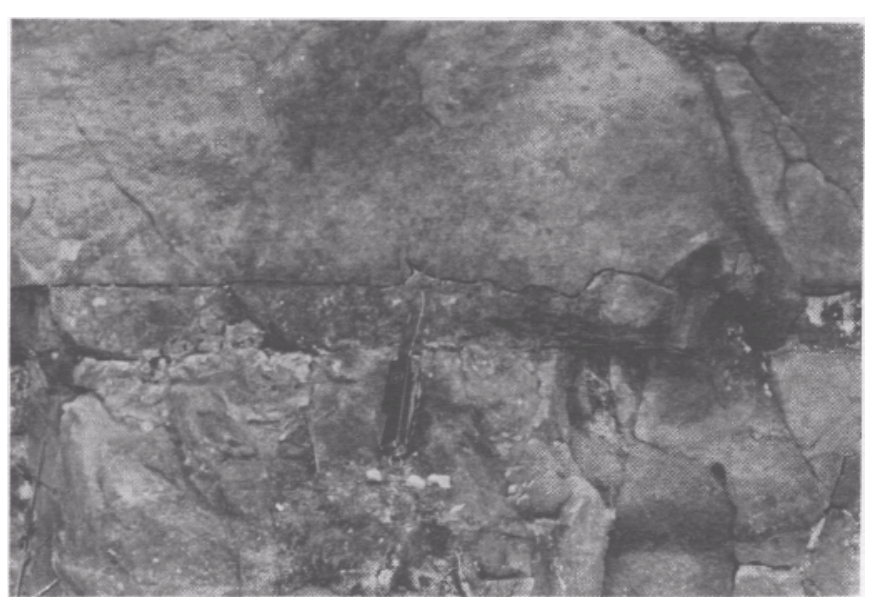

Foto 18 - Afloramento 6 - Boituva, km 0,5 da SP-129. Arenito fino, maciço com estruturas de sobrecarga

Photo 18 - Outcrop 6 - Boituva (SP-129, km 0,5). Fine massive sandstone with load cast (flame structure)

A exemplo do afloramento anterior a fácies Srg é representada por camadas centimétricas ou decimétricas (Foto 15), com a granulação muito fina a síltica e freqüentes laminações cruzadas cavalgantes dos tipos A, B e C. Por vezes, o aca mamento se mostra ondulado ou lenticular, com incipiente gradação normal (Foto 16). Outro tipo de arenito, igualmente muito fino a síltico, se apresenta em camadas centimétricas, marcadamente com laminação plano-paralela horizontal e sem evidência de gradação; corresponde à fácies Sh.
Os finos são de tonalidades mais escuras, com laminação horizontal de cor e textura. Seixos pingados são freqüentes, configurando a fácies Fld.

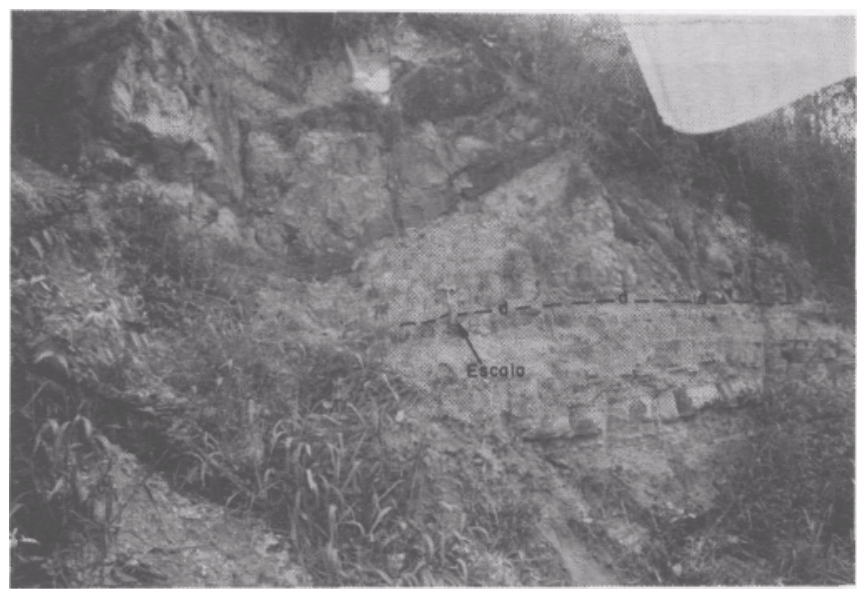

Foto 19- Visão parcial do afloramento 6 (Boituva), mostrando a superficie de deslizamento (d) concordante com o acamamento, sobre a qual o pacote superior fluiu plasticamente Photo 19 - Partial view of outcrop n. 6 (Boituva), showing the sliding surface (d) in concordance with the bedding plane, on which the upper package flowed plasticly

Essas fácies associam-se em dois padrões de ritmicidade diferentes, (Foto 17). No primeiro, o caráter rítmico é emprestado pela própria fácies $\mathrm{Fl}$, cuja laminação horizontal separa estratos milimétricos a centimétricos de silte e argila com contato abrupto; por vezes, a lâmina clara é representada pela fácies arenosa Sh. Em ambos os casos, a ritmicidade resultante apresenta o aspecto várvico. No segundo padrão, a ritmicidade é conferida pela alternância das fácies $\mathrm{Srg}$ e $\mathrm{Fl}$, ou seja, alternância entre depósitos tracionais e de decantação idênticos aos da Litofácies Ritmitos Gradados, já estudada. A Litofácies Ritmitos Várvicos possui sua ritmicidade conferida por fatores texturais envolvidos na decantação, exclusivamente (fácies Fl ou $\mathrm{Fl} / \mathrm{Sh}$.

A coexistência dos processos de tração e decantação nos Ritmitos Gradados indica correntes de turbidez de baixa concentração como processo deposicional. Estes depósitos correspondem aos turbiditos Ted de Bouma. Por outro lado, os

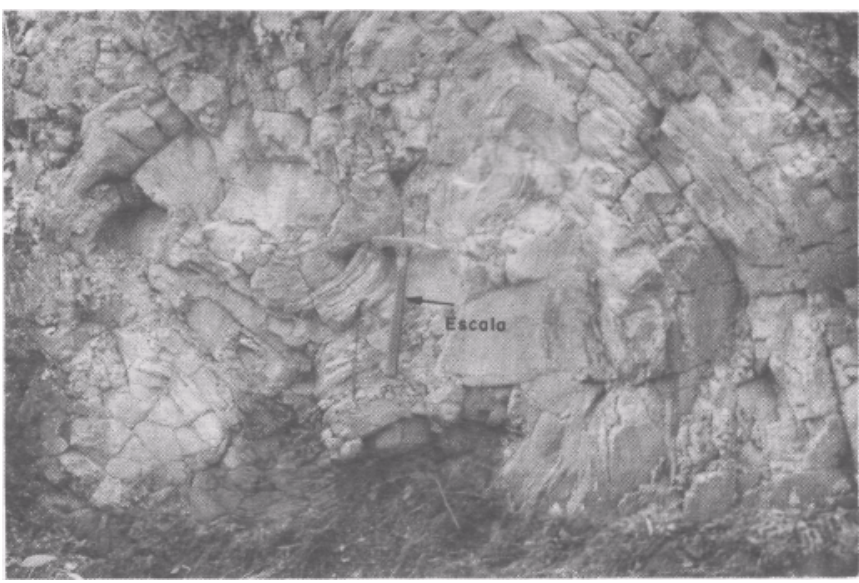

Foto 20 - Detalhe das deformações da pane superior do afloramento 6 (Boituva). Sentido do fluxo de E para $W$ (direita para esquerda)

Photo 20 - Detail of the deformation on the upper part of the outcrop 6 (Boituva). Flow direction is from $\mathrm{E}$ to $\mathrm{W}$ (right to left in the photo) 
Ritmitos Várvicos seriam derivados das nuvens caudais das mesmas correntes de turbidez com possível interferência sazonal de suspensões superficiais.

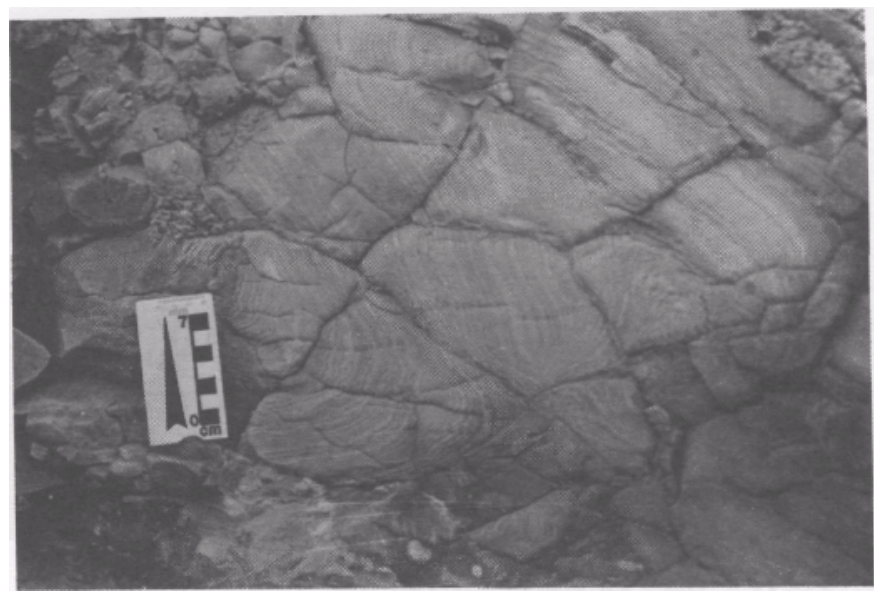

Foto 21 - Detalhe dos ritmitos deformados, evidenciando dobras e microfalhas (afloramento 6 - Boituva)

Photo 21 - Detail of the deformed rhythmite evidencing folds and microfaults (outcrop 6 - Boituva)

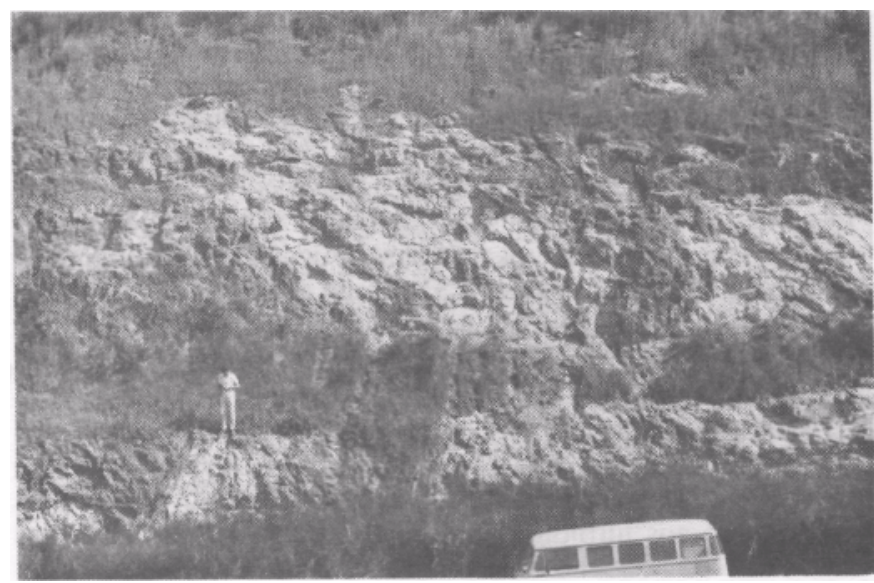

Foto 22 - Vista parcial do afloramento 7 (SP-127, km 98,3) Diamictitos deformados. Notar no lado esquerdo inferior dobra com plano axial vertical (escala na crista da dobra)

Photo 22 - Partial view of outcrop 7 (SP-127, km 98.3). Deformed diamictite. Note at the lower left side a fold with a vertical axial plan (scale on the fold crest)

Afloramento 6 - Boituva Localizado no $\mathrm{km} \mathrm{0,5}$ da Rodovia Vicente Palma (SP - 129), este afloramento tem sido visitado por muitos geólogos e estudantes desde há muitos anos devido à notável exposição de deformações plásticas, que caracterizam a Litofácies Ritmitos Deformados. A seqüência aflorante apresenta, como característica geral, granodecrescência ascendente (fining upward) acompanhado, grosso modo, a diminuição na espessura das camadas (thinning upward).

A seção basal, unidades de 1 a 6 na figura 6 , é constituída de ritmitos caracterizados principalmente por um predomínio de arenitos maciços $(\mathrm{Sm})$ com clastos de argilito, correspondentes à Ta de Bouma (1962) (Foto 18) e lamitos e/ou ritmitos finos (Fl) intercalados subordinadamente. A espessura das camadas mais basais da seção é de porte métrico, passando a centimétrico nas camadas superiores.

Até a camada 6 não se notam deformações internas. São marcantes, no entanto, as estruturas de sobrecarga, principal- mente visíveis nas unidades 4 e 5 . Observa-se, também, a amalgamação de lentes de arenito muito fino/fino, maciço, separadas por argilito e com marcas de sobrecarga na base de cada corpo. Fragmentos vegetais carbonificados podem ser encontrados em camadas do topo da seção basal (base da camada 6).

As deformações começam a ser registradas a partir da unidade 6 (superfície de deslizamento), primeiramente internas a esta unidade, e tornando-se a feição marcante acima desta (Foto 19), primeiro em ritmitos (Fl) com lentes e camadas arenosas $(\mathrm{Sm})$ e posteriormente em ritmitos finos (Fl) (Foto 20), nos quais são observadas inúmeras microfalhas (Foto 21).

Pelos dados analisados infere-se que os arenitos maciços (Sm) da porção basal da sequiência estudada resulta de um empilhamento de fácies geradas por correntes de turbidez, de diferentes intensidades, derivadas de eventos discretos de transbordamentos de canais subaquosos. A superfície de deslizamento, sobre a qual desenvolveu-se o processo de ressedimentação (deslizamentos) dos turbiditos desconfinados, mais diluídos (Fl), marca o final dos eventos de transbordamento.

A seção aqui analisada corresponde aos dezoito metros superiores da coluna ilustrada na figura 8 do trabalho de Rocha-Campos (1972), que também infere deslizamentos subaquosos como processos geradores das deformações plásticas (Rocha-Campos 1967).

Afloramento 7 - SP-127 O último afloramento deste

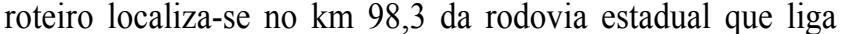
Cerquilho a Tatuí, SP-127, no vale do Rio Sorocaba. Representa a Litofácies Diamictitos Deformados, que se acham expostos num corte superior a $70 \mathrm{~m}$ de extensão por $20 \mathrm{~m}$ de altura, aproximadamente (Foto 22).

Os diamictitos são de cor cinza claro, com baixa proporção de seixos e grânulos quartzosos e líticos, em dimensões milimétricas a decimétricas. Os matacões são raros e, quando ocorrem, são arredondados ou facetados e dispersos em matriz síltica-arenosa.

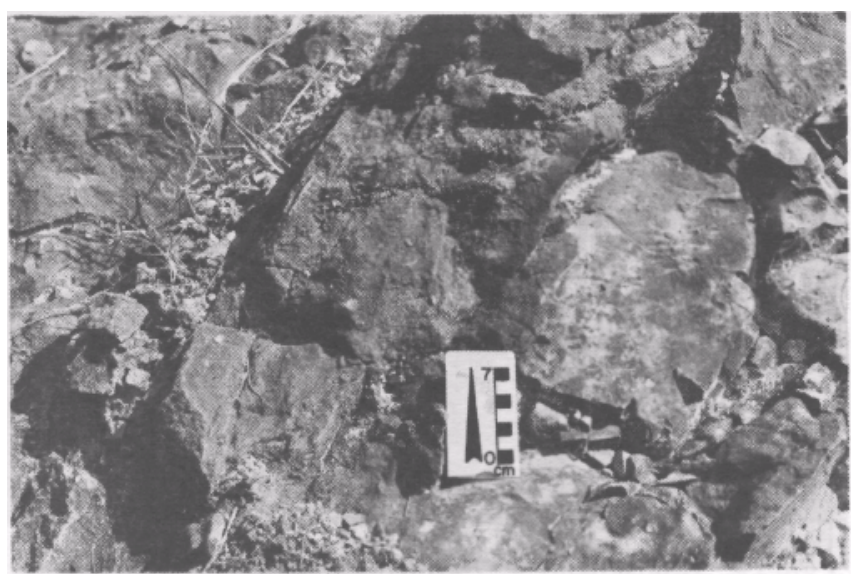

Foto 23 - Detalhe parcial da dobra indicada na foto anterior, ressaltada pela intercalação de camada subvertical de arenito laminado com gradação (fácies $\mathrm{Shg}$ ) em diamictito deformado (afloramento 7 - SP-127)

Photo 23 - Partial detail of the fold indicated in the former photo, emphasized by the intercalation of subvertical graded laminated sandstone bed (facies Shg) into a deformed diamictite (outcrop 7 - SP-127)

O grau de deformação é relativamente intenso, o que empresta um aspecto geral maciço ao afloramento, sugerindo uma fluidização parcial. Não obstante, dobras e outras feições convolutas podem ser reconhecidas pela preservação parcial dos acamamentos originais (Foto 23). Este fato, reforçado pela 
presença de camadas arenosas com laminação horizontal e gradação normal, evidencia um certo grau de organização dos diamictitos originais.
Deslizamentos gravitacionais subaquosos de diamictitos organizados, ainda não totalmente consolidados, é a interpretação postulada para este afloramento.

\section{REFERÊNCIAS BIBLIOGRÁFICAS}

AB'SABER, A.N. 1948. Seqüência de rochas glaciais e sub-glaciais dos arredores de Itu, São Paulo. Mineração e Metalurgia, 13(73):43-45.

BARBOSA, O. \& ALMEIDA, F.F.M. 1949. Nota sobre a estratigrafia da Série Tubarão, no Estado de São Paulo. An. Acad. bras. Ciên., 21(1):65-68.

BOUMA, A.H. 1962. Sedimentology of Some Flysch Deposits. Amsterdam, Elsevier. $168 \mathrm{p}$

FERNANDES, A.C.S.; CARVALHO, E.S.; NETTO, R.G. 1987. Comentários sobre os tracos fósseis do paleolago de Itú, São Paulo. In: SIMP. REG. GEOL.,6.RioClaro, 1987. Atas... Rio Claro, SBG/NSP. v. 1, p. 297-311.

JOPLING, A. V. \& WALKER, R.G. 1968. Morphology and origin of ripple-drift cross-lamination, with examples from the Pleistocene of Massachusetts. $J$. Sed. Petrol., 38(4):971-984.

LEONARDOS, O.H. 1938. Varvitos de Itu, São Paulo. Mineração e Metalurgia, 3(15):157-159.

MEZZALIRA, S. 1966. Fósseis do Estado de São Paulo. São Paulo, IGG. 132 p. (Boletim 45).

MEZZALIRA, S. 1969. Geologia de subsuperfície em Itu, SP. Ocorrência de "Rocha Moutonée" nos testemunhos de sondagem. An. Acad. bras. Ciên. 41:83-89.

PETRI, S. 1985. Ritmitos de Itu. In: SIMP. REG. GEOL., 5. São Paulo, 1985. Atas... São Paulo, SBG/NSP. v. 1, p. 235-241.
PICKERING, K.; STOW, D.; WATSON, M.; HISCOTT, R. 1986. Deep water facies, processes and models. A review and classification scheme for modern and ancient sediments. Earth Science Reviews, 23:75-174.

ROCHA-CAMPOS, A.C. 1967. The Tubarão Group in the Brasilian portion of the Paraná Basin. In: BIGARELLA, J.J.; BECKER, R.R.; PINTO, I.D. eds. Problems in Brazilian Gondwana Geology. Curitiba, IG/UFPR. p. 27-102.

ROCHA-CAMPOS, A.C 1972 Late Paleozoic Geology of Northern Paraná Basin. In: INT. SYMP. CARB. PERMIAN SYSTEMS IN SOUTH AMERICA. São Paulo, 1972. Excursion Guide-book... São Paulo, p. 3-69.

ROCHA-CAMPOS, A.C \& SUNDARAM, D 1981. Geological and palinological observations on Late Paleozoic varvites from the Itararé Subgroup Paraná Basin. In: CONGR. LATINO-AM. PALEONT., 2. Porto Alegre, 1981. Anais... Porto Alegre, SBP. v. 1, p. 257-275.

MANUSCRITO A699

Recebido em 8 de abril de 1991 Revisão do autor em 18 de fevereiro de 1992 Revisão aceita em 26 de fevereiro de 1992 